\title{
Accessibility of outpatient healthcare providers for wheelchair users: Pilot study
}

\author{
Karen L. Frost, PhD, MBA; $;^{*}$ Gina Bertocci, PhD, PE; ${ }^{1}$ Michael D. Stillman, MD; ${ }^{2}$ Craig Smalley, MEng; ${ }^{1}$ \\ Steve Williams, $\mathbf{M D}^{3}$ \\ ${ }^{1}$ Department of Bioengineering, J. B. Speed School of Engineering, University of Louisville, Louisville, KY; Depart- \\ ments of ${ }^{2}$ Internal Medicine and ${ }^{3}$ Physical Medicine and Rehabilitation, School of Medicine, University of Louisville, \\ Louisville, $\mathrm{KY}$
}

\begin{abstract}
The Americans with Disabilities Act (ADA) requires full and equal access to healthcare services and facilities, yet studies indicate individuals with mobility disabilities receive less than thorough care as a result of ADA noncompliance. The objective of our pilot study was to assess ADA compliance within a convenience sample of healthcare clinics affiliated with a statewide healthcare network. Site assessments based on the ADA Accessibility Guidelines for Buildings and Facilities were performed at 30 primary care and specialty care clinics. Clinical managers completed a questionnaire on standard practices for examining and treating patients whose primary means of mobility is a wheelchair. We found a majority of restrooms (83\%) and examination rooms (93\%) were noncompliant with one or more ADA requirements. Seventy percent of clinical managers reported not owning a heightadjustable examination table or wheelchair accessible weight scale. Furthermore, patients were examined in their wheelchairs $(70 \%-87 \%)$, asked to bring someone to assist with transfers (30\%), or referred elsewhere due to an inaccessible clinic (6\%). These methods of accommodation are not compliant with the ADA. We recommend clinics conduct ADA selfassessments and provide training for clinical staff on the ADA and requirements for accommodating individuals with mobility disabilities.
\end{abstract}

Key words: accessibility, accessible healthcare, accommodation, ADA, Americans with Disabilities Act, equal access, medical device, mobility disability, wheelchair, wheelchair users.

\section{INTRODUCTION}

The Americans with Disabilities Act (ADA) of 1990 was enacted more than 20 years ago to prohibit discrimination against individuals with disabilities in everyday activities, including medical services [1]. Despite its enactment more than 2 decades ago, evidence indicates that our nation's healthcare system remains inaccessible to individuals with physical disabilities and that many providers lack knowledge of the law's mandate [2-4].

The ADA requires full and equal access to healthcare services and the facilities where these services are provided. Public hospitals, clinics, and medical offices operated by State and local governments are covered by Title II of the ADA as public entities. Private hospitals or medical offices are covered by Title III as places of public accommodation. Providers are required to make reasonable

Abbreviations: $\mathrm{ADA}=$ Americans with Disabilities Act, ADAAG = ADA Accessibility Guidelines for Buildings and Facilities, DOJ $=$ Department of Justice, SCI $=$ spinal cord injury.

*Address all correspondence to Karen L. Frost, PhD, MBA; Department of Bioengineering, J. B. Speed School of Engineering, Lutz Hall, Rm 419, University of Louisville, Louisville, KY 40208; 502-645-4734.

Email: k.bertocci@louisville.edu

http://dx.doi.org/10.1682/JRRD.2015.01.0002 
modifications to policies, practices, and procedures to ensure services are fully available to individuals with disabilities unless the modifications will fundamentally alter the essential nature of the services. This means removing architectural barriers or adopting alternative measures, such as relocating activities to accessible locations [5]. Additionally, under the Patient Protection and Affordable Care Act [6], the U.S. Access Board was tasked with issuing new standards that allow for independent access and use of medical diagnostic equipment (e.g., examination tables, examination chairs, weight scales, mammography equipment, and other imaging equipment) used in physicians' offices, clinics, emergency rooms, and hospitals. A Notice of Proposed Rulemaking, titled "Proposed accessibility standards for medical diagnostic equipment," was published in 2012, but to date no final rule has been adopted [7].

A number of previous studies describe the challenges people with disabilities face when attempting to access medical facilities [2-8] and participate in disease prevention efforts [6-7]. Veltman et al. surveyed individuals with physical disabilities and found that 32 percent had difficulty accessing their family doctor's office and 38 percent had difficulty accessing medical equipment [9]. Perhaps more importantly, 19 percent felt they received inadequate care and 22 percent perceived that their disability prevented them from receiving appropriate care [9]. More recently, Stillman et al. surveyed wheelchair users with spinal cord injury (SCI) and found that 77 percent of patients could not access the examination table in primary care settings and 89 percent had not been weighed during their visit [10]. Physical accessibility barriers included narrow hallways or doorways that prevented entry to or within a clinic, examination tables that were not height-adjustable, and check-in counters and restrooms that were inaccessible to wheelchair users.

Several studies have examined compliance with the ADA in outpatient healthcare settings. Bachman et al. reported that 20 percent of physician facilities did not have automated doors or accessible restrooms and examination rooms and 40 to 50 percent lacked staff capable of helping wheelchair users transfer from their wheelchair to an examination table, dress or undress, or use the restroom [3]. Grabois et al. found that 69 percent of primary care and obstetrician/gynecology providers did not own an adjustable-height examination table and only 2 percent owned a scale suitable to assess weight for patients who remained seated in a wheelchair [2].
Equal access to healthcare is a pressing issue in the United States. The consequences of access barriers that prevent or delay patients from obtaining healthcare are widespread and include deteriorating physical health and economic, social, and psychological consequences [8]. The objective of this pilot study was to assess compliance with current ADA regulations on access to equal healthcare for individuals with mobility disabilities using a convenience sample of primary care and specialty care healthcare clinics affiliated with a statewide healthcare network. We evaluated clinics with wheelchair users in mind, because this subset represents those with the most severe mobility limitations. In addition to ADA site assessments, we surveyed clinical managers to obtain objective data that may be useful to healthcare providers in remedying common deficiencies. Based on our findings, recommendations are provided for improving access to quality healthcare and areas of future research.

\section{METHODS}

A convenience sample of healthcare clinics affiliated with a statewide healthcare network was used in this study. Facilities and clinics located within a $24 \mathrm{~km}$ (15 mi) radius of Louisville, Kentucky, were assessed for compliance with the ADA between September 2013 and September 2014. In part one of this study, investigators coordinated site assessments with facility representatives and clinic managers. In part two, clinical managers were asked to complete a 10-item survey.

\section{Part 1-Site Assessment}

A standardized protocol for recording key measurements was created to assess ADA compliance based on the current U.S. Department of Justice (DOJ) Civil Rights Division's “Access to medical care for individuals with mobility disabilities" [5] and the ADA Accessibility Guidelines for Buildings and Facilities (ADAAG) [11]. Dimensions to accommodate a "common wheelchair," defined by the ADA as a wheeled mobility device measuring $122 \mathrm{~cm}$ (48 in.) length by $76 \mathrm{~cm}$ (30 in.) width, were used for assessment. All measurements were performed by a master's level research engineer (C. Smalley), who was trained and supervised by a licensed professional engineer (G. Bertocci). Physical measurements and features were categorized based on commonality to the facility, clinic, or examination room and are outlined in 
Table 1. Each architectural element was rated ADA compliant or noncompliant.

\section{Part 2-Clinical Manager Survey}

Clinical managers were asked to complete a 10-item questionnaire on standard practices for examining and treating patients whose primary means of mobility is a wheelchair. Development of the questionnaire was informed by the clinical experiences of Drs. Stillman (primary care setting) and Bertocci (assistive technology clinic) and the DOJ's "Access to medical care for individuals with mobility disabilities" [5]. As shown in Table 2, the questionnaire included multiple response items and open-ended questions. Responses to questions 6 and 8 were validated by telephone using a script in which the interviewer posed as a caregiver seeking to make an appointment for a family member who was a wheelchair user and unable to ambulate. The interviewer asked how the patient would be examined at the clinic and what equipment and/or assistance was available to aid in transferring the patient to the examination table to ensure a complete medical examination. If the caller was told the patient would be examined while remaining seated in his or her wheelchair, the caller insisted the patient be placed on an examination table and again asked how this would be accomplished. Descriptive statistics were performed on site assessment outcomes and clinical manager surveys (SPSS version 21 [IBM Corp; Armonk, New York]).

\section{RESULTS}

A total of 30 clinics ( 5 primary care, 25 specialty care) participated in the study (Figure 1). Clinics were located among 10 buildings across four healthcare facilities. The percentage of wheelchair-seated patients seen at

Table 1.

Physical measurements and features assessed for compliance with Americans with Disabilities Act. Clinical managers were asked to direct research team to examination room that would be used to examine patient who was wheelchair user.

\begin{tabular}{|c|c|}
\hline Architectural Element & Primary Characteristics Assessed \\
\hline \multicolumn{2}{|l|}{ Facility } \\
\hline Accessible Entry & Accessible ramp or street-level entry. \\
\hline Exterior Door & $\begin{array}{l}\text { Type (automated/manual), operating hardware (handle, pull, latch, knob), and } \\
\text { width (when open } 90^{\circ} \text { ). }\end{array}$ \\
\hline \multicolumn{2}{|l|}{ Clinic } \\
\hline Entry Door & $\begin{array}{l}\text { Type (automated/manual), operating hardware (handle, pull, latch, knob), and } \\
\text { width (when open } 90^{\circ} \text { ). }\end{array}$ \\
\hline Reception/Sign-in Counter & $\begin{array}{l}\text { Height, depth, and wheelchair clearance area below counter to accommodate for- } \\
\text { ward or side reach. }\end{array}$ \\
\hline Interior Doorway(s) & $\begin{array}{l}\text { Type (automated/manual), operating hardware (handle, pull, latch, knob), and } \\
\text { width (when open } 90^{\circ} \text { ). }\end{array}$ \\
\hline Accessible Route & $\begin{array}{l}\text { Dimensions of corridors/hallways/walks (width, length), including turning spaces } \\
\text { for wheelchairs. }\end{array}$ \\
\hline \multicolumn{2}{|l|}{ Restroom } \\
\hline Doorway & Width and swing to accommodate accessible route. \\
\hline Accessible Route & $\begin{array}{l}\text { Dimensions of clear path to stall/toilet/sink (width, length), including clear floor } \\
\text { space and wheelchair turning space to accommodate common wheelchair. }\end{array}$ \\
\hline Sink and Mirror & $\begin{array}{l}\text { Sink and counter heights, faucet type, clearance area below sink (to allow for use } \\
\text { by wheelchair users), mirror height. }\end{array}$ \\
\hline Grab Bars & Dimensions and placement near toilet. \\
\hline \multicolumn{2}{|l|}{ Examination Room } \\
\hline Weight Scale & Presence or absence of wheelchair accessible weight scale. \\
\hline Accessible Route & $\begin{array}{l}\text { Dimensions of pathway into examination room (width, length), including clear } \\
\text { floor space and wheelchair turning space to accommodate common wheelchair. }\end{array}$ \\
\hline Examination Table & $\begin{array}{l}\text { Adjustable to between } 43 \text { and } 48 \mathrm{~cm} \text { (17-19 in.) above floor; with grab bars and/ } \\
\text { or positioning aids available. }\end{array}$ \\
\hline Transfer Aids & Transfer board, sling lift, trained staff assistance. \\
\hline
\end{tabular}


Table 2.

Questions and response choices for clinical manager survey.

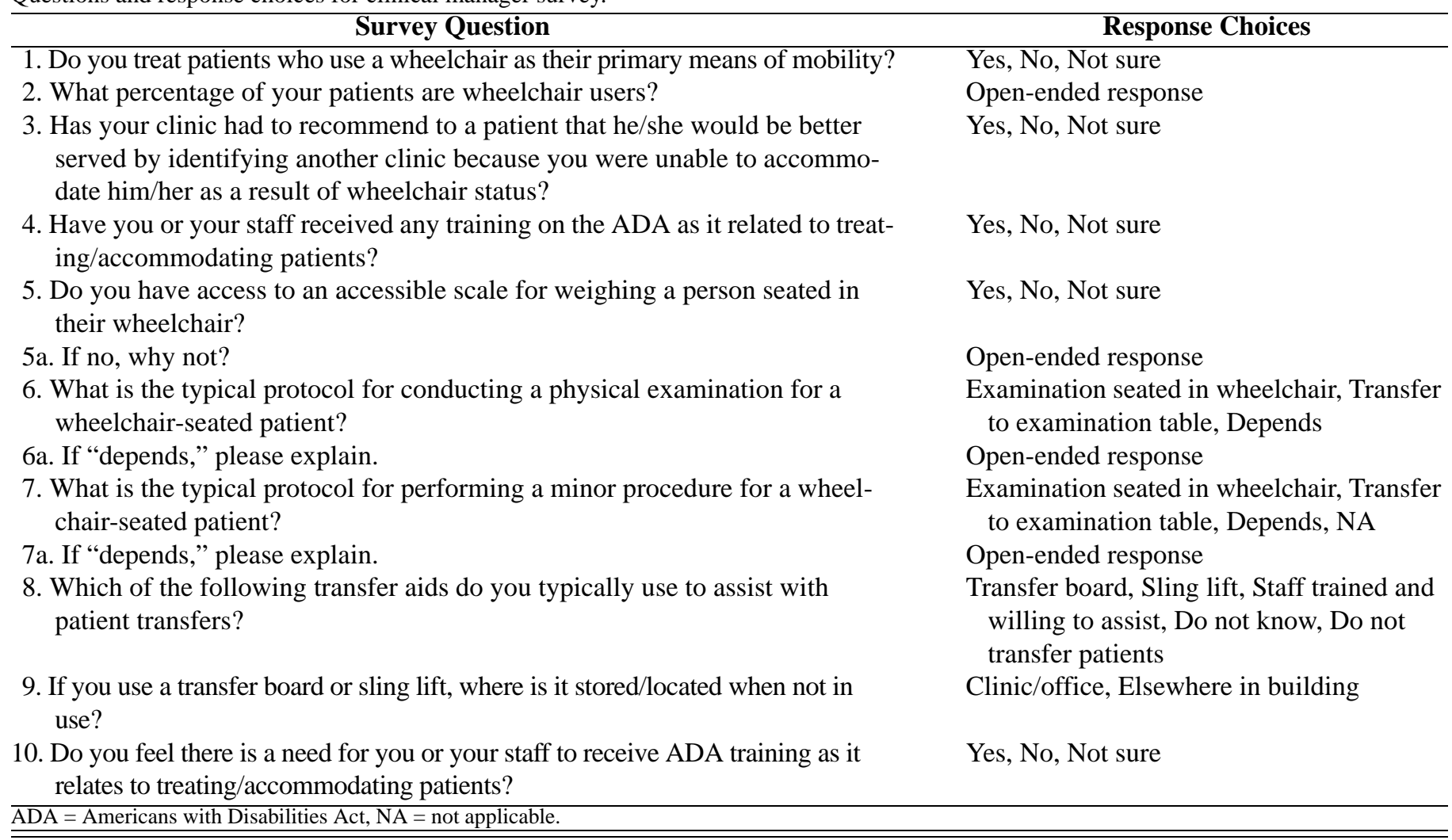

each clinic ranged from 0.5 to 40.0 percent, with the majority (63.3\%) reporting that $\leq 5.0$ percent of their patients used a wheelchair.

\section{Part 1-Site Assessment}

\section{Facility and Clinic Architectural Characteristics}

Figure 2 summarizes the percentage of clinics compliant with major architectural and equipment elements based on site assessment results. All facilities were accessible via ramp or street-level entry, and all exterior doors were equipped with an automatic door opener. Within each facility, entry doors for all clinics were ADA compliant, with just one primary care clinic failing to meet the requirement for an interior door with a minimum clear opening of $812.8 \mathrm{~mm}$ (32 in.) [11]. All interior clinic corridor dimensions met the ADA requirements for an accessible route.

The majority of clinic restrooms (83\%) did not meet one or more ADA requirements for accessibility (20\% primary care, $80 \%$ specialty care clinics). Within this subset, several restrooms (16\%) were equipped with doors that improperly swung into required clear floor space (25\% primary care, $75 \%$ specialty care clinics). The ADA-specified minimum distance from the toilet to a wall or other obstruction (457.2 mm [18 in.]) was violated in 60 percent of these restrooms (87\% primary care, $13 \%$ specialty care clinics); a smaller percentage (16\%) did not provide sufficient clear floor space. However, most noncompliant conditions occurred at or around the sink area (76\%) and ranged from inadequate knee, toe, or vertical clearance beneath the sink (40\% overall: $20 \%$ primary care, $80 \%$ specialty care clinics) to placement of mirrors greater than the maximum allowable $101.6 \mathrm{~cm}$ (40 in.) above the floor (56\% overall: $14 \%$ primary care, $86 \%$ specialty care clinics). More than one-third of these restrooms (36\%) did not meet $\mathrm{ADA}$ requirements for length or placement of grab bars adjacent to the toilet (33\% primary care, 67\% specialty care clinics) [11].

\section{Examination Room Architectural and Equipment Characteristics}

Accessible weight scales were absent from all primary care clinics and approximately two-thirds of specialty 


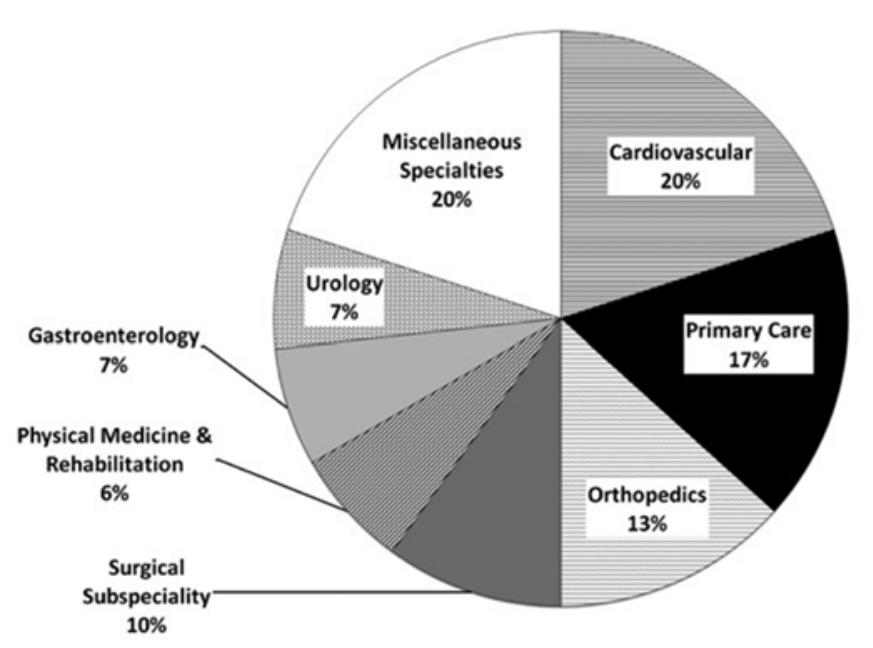

Figure 1.

Percentage distribution of healthcare clinics that participated in Americans with Disabilities Act site assessments.

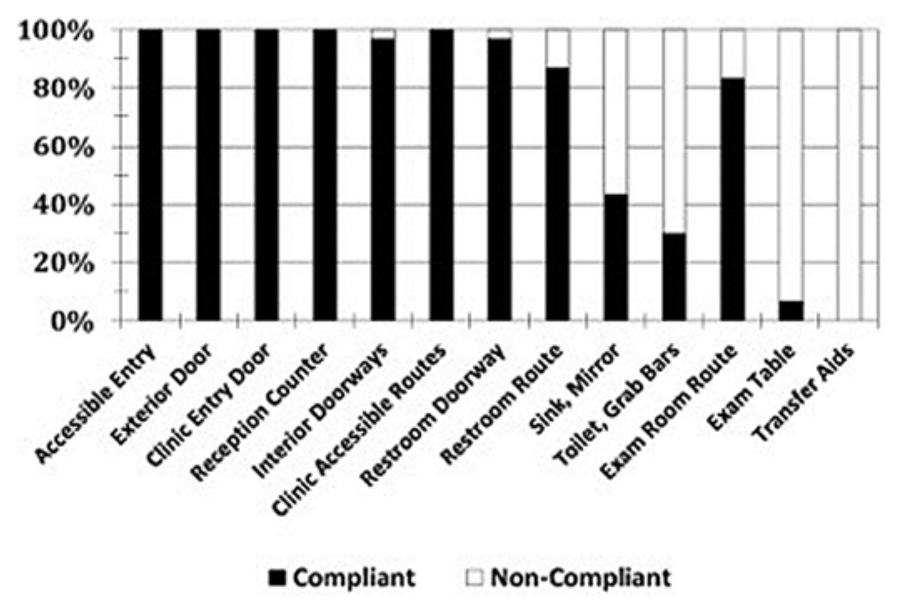

Figure 2.

Percentage of clinics rated compliant for each assessed architectural/equipment element $(n=30)$ based on site assessments. Note: "Exam Table" bar indicates only presence or absence of an adjustable-height examination table.

care clinics (64\%). Sixteen percent of specialty care clinics reported they did not weigh any patients, and thus did not have a weight scale.

Overall, the majority of inspected examination rooms were not compliant with one or more ADA accessibility requirements (93\%) (Figure 3). Eighty percent of primary care and sixty-five percent of specialty care clinics were not equipped with a height-adjustable examination table

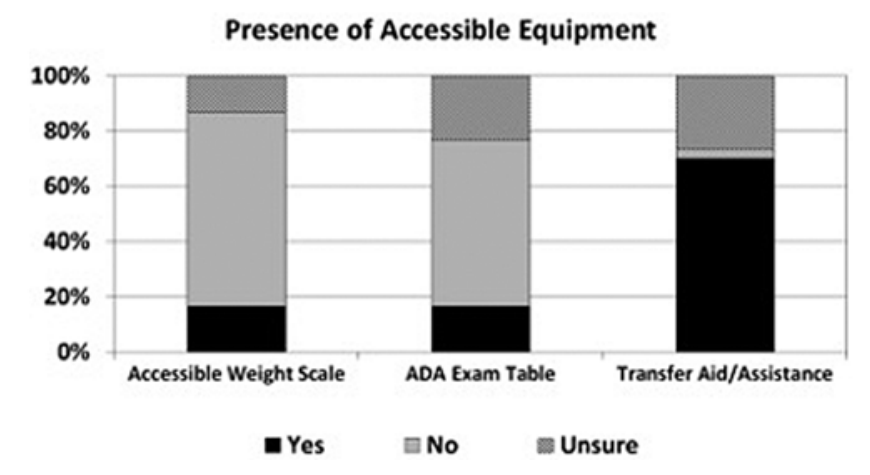

Figure 3.

Presence of accessible equipment in primary care and specialty care clinics based on clinical manager survey responses $(n=30)$.

that lowered to the required height of between 43 and $48 \mathrm{~cm}$ (17-19 in.) [11]. Armrests or support rails (either attached to or separate from the examination table) to assist with transfers or provide positioning support were absent in 20 percent of primary care and 28 percent of specialty care clinics. Two examination rooms, one primary care and one specialty care, did not meet the ADA accessible route requirement for providing a clear pathway to the examination table (minimum pathway measuring $91.4 \mathrm{~cm}$ [36 in.] width), and several provided either insufficient clear floor space adjacent to the examination table or insufficient wheelchair turning space (20\% primary care, $12 \%$ specialty care clinics).

\section{Part 2-Clinical Manager Survey}

The majority of clinics reported treating patients who use a wheelchair as their primary means of mobility. However, two clinics (one primary care, one specialty care) reported that they refer wheelchair-seated patients elsewhere due to their inability to accommodate them.

When surveyed at the time of the site assessment, 70 percent of clinical managers reported wheelchair users were examined while they remained seated in their wheelchair ( $60 \%$ of primary care, $72 \%$ of specialty care clinical managers). Twenty-two percent stated the decision to transfer depended on the patient's ability to transfer independently or with assistance and whether or not the physician required the patient be transferred to the examination table (40\% primary care, $20 \%$ specialty care clinical managers). Eight percent of specialty care clinics stated there was no need to transfer patients given the nature of the practice (e.g., psychiatry, foot and ankle orthopedic practices). 
Approximately one-third of specialty care clinics (32\%) reported performing minor in-office procedures. Of this subset, 43 percent transferred patients to an examination table for a minor procedure and 36 percent performed the procedure while the patient remained seated in his or her wheelchair. None of the primary care clinics reported performing minor in-office procedures. All clinical managers reported that their staff was "trained and willing to assist" with transfers, yet none had access to transfer boards or sling lifts.

Telephone validation of examination practices revealed discrepancies between survey responses and post hoc telephone responses (one specialty care clinic closed permanently after the site assessment visit; for analysis purposes, the survey response was carried forward). When asked by telephone, 87 percent of clinical managers reported wheelchair users would be examined while they remained seated in their wheelchair $(80 \%$ primary care, $88 \%$ specialty care clinical managers). When the caller insisted the patient be placed on the examination table in order to receive an equitable medical examination, 10 clinical managers stated the patient would need to bring a friend or family member to the appointment to help with transferring (60\% primary care, $28 \%$ specialty care clinical managers). Three additional clinical managers stated their staff was unable to help lift patients (but did not explicitly request the patient bring someone to assist), and two clinical managers (one primary care, one specialty care) recommended the patient seek treatment at the nearby university hospital.

Two questions were asked to gauge awareness of the need for ADA training of clinical staff pertaining to accommodating patients who use wheelchairs. At the beginning of the survey, clinical managers were asked whether or not they or their clinical staff had received training on the ADA related to caring for patients with a disability. At the end of the survey, they were asked Whether they felt there was a need for ADA training of clinical staff related to patient care. Few clinical managers (23\% overall: $20 \%$ primary care, $24 \%$ specialty care clinical managers) felt there was a definitive need for staff training (Figure 4), despite self-reported low rates of ADA compliance.

\section{DISCUSSION}

This pilot study evaluated compliance of 30 affiliated outpatient medical clinics with ADAAG [11] and U.S.

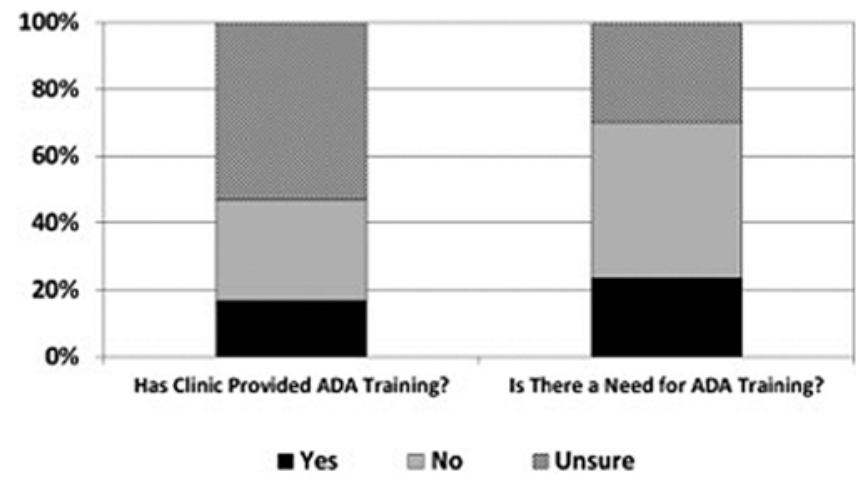

Figure 4.

Clinical manager awareness of potential need for Americans with Disabilities Act (ADA) training $(n=30)$.

DOJ requirements [5] and identified barriers to healthcare access. Five important findings are presented regarding accessible equipment, knowledge of $\mathrm{ADA}$ requirements for patient care, and facility/architectural barriers. The majority of clinics (1) did not have an accessible examination table, (2) examined patients while they remained seated in their wheelchairs, (3) requested the patient bring someone to assist them in transferring to the examination table as needed, (4) did not own or have access to a weight scale that could be used to weigh a wheelchair user, and (5) did not meet one or more ADA requirements for an accessible restroom.

First, two-thirds of clinics assessed did not have height-adjustable examination tables capable of lowering to the height of a wheelchair seat and equipped with a support rail for stabilization. This finding parallels results of a national survey conducted by Winters et al. in which respondents with mobility disabilities ranked examination tables as the most difficult medical device to access or use [12]. Although not explicitly required for ADA compliance, in the absence of a patient lift or staff trained and skilled in assisting patient transfers, a height-adjustable examination table is usually necessary and may help prevent injury to patients, staff, and physicians [12]. An Internet search of fixed-height versus adjustable-height examination tables available from major manufacturers revealed pricing ranging from $\$ 1,950$ to $\$ 8,500$ USD. While these expenditures are not inconsiderable, they may be less daunting than many physicians fear given the availability of Federal tax credits and deductions to offset expenses [5]. However, even if a height-adjustable examination table is present, some patients may not be able to 
transfer safely and independently and may require additional assistance. In these circumstances, staff assistance, a transfer board, or patient lift may be required. Patients unable to pivot from their wheelchair to the examination table may benefit from a transfer board or stabilization from clinical staff. Other patients may only be able to transfer with the aid of a mechanical lift or manual lifting by clinical staff. Mechanical lifts are a safer means of transferring a patient, reducing the likelihood of injury to both patient and staff. Back injuries are common among healthcare workers and many occur when transferring patients [13]. Patient injuries may also result from handling by healthcare workers untrained in proper lifting techniques [14]. Portable mechanical lifts can be stored elsewhere when not in use; however, they require sufficient clear space adjacent to the examination table to accommodate the lift and operation.

A second important finding of our study is that wheelchair users are nearly always examined while they remain seated in their wheelchair. During our site visits, more than one-half of clinic managers reported transferring wheelchair patients to a table for examination; yet when pressed, this percentage dropped to less than 25 percent of clinics. In retrospect, this is not surprising given our site observations that few clinics owned an ADA-compliant examination table. It is also consistent with findings of others obtained by surveying physicians, practice managers, and patients regarding healthcare services provided to patients with mobility and other disabilities [2,10,15-16]. It also reinforces our previous study of wheelchair users with SCI, in which 85 percent of patients with SCI reported being examined while they remained seated in their wheelchairs and nearly twothirds believed they had been offered incomplete medical care because of their disability [10]. While some examinations (e.g., ear, nose, and throat) may be provided equitably whether or not the patient is seated in a wheelchair or on an examination table, standard protocols often require the patient to be placed in a supine or prone position to permit palpation or further examination/testing. Performing such examinations while a patient remains seated in a wheelchair results in lower quality of care and a disparity between healthcare services provided to those with and without a disability. In accordance with the ADA, the same standard of care must apply to all patients.

Our third finding is the requirement that wheelchair users bring a friend or family member to the appointment to help with transfers. This requirement was voiced explicitly by a third of clinical managers. Three additional clinical managers did not explicitly request the patient bring someone to assist; however, they stated their staff was unable to provide transfer assistance, and two others recommended the patient seek treatment at the nearby university hospital where they believed accommodations could be provided. This finding reinforces earlier studies indicating a troubling lack of knowledge of ADA requirements by healthcare providers [13,15-16]. Under the ADA, healthcare providers must provide reasonable assistance so patients with disabilities can receive care [5]. Patients with and without disabilities may choose to bring someone with them or go alone to a healthcare appointment. However, healthcare providers cannot ask a patient with disabilities to bring someone with them. Findings that healthcare clinics lack accessible examination tables, examine patients while they remain seated in their wheelchair, and request patients bring someone to assist them as needed indicate that there is an unmet need for information and training on the ADA's requirement for full and equal access to healthcare services.

Our fourth finding, that wheelchair-accessible scales were not available in 70 percent of clinics, suggests clinicians do not have an accurate measure of wheelchair users' mass in their medical records and reinforces an overall impression that individuals with mobility disabilities receive less than thorough care. Patient mass is not only key for assessing overall health, it is critical for the safe provision of pharmaceuticals. We priced wheelchairaccessible weight scales from several national vendors using an Internet search and found prices ranging from $\$ 1,675$ to $\$ 3,350$ USD.

Finally, we identified a variety of deficiencies resulting in inaccessible restrooms among the majority of clinics. Door swings, obstructions, and overall lack of clear floor space may prevent wheelchair users from safely positioning themselves to use the toilet. Misplaced or undersized grab bars may conspire to the same effect. Additionally, personal hygiene may be impeded if a wheelchair user cannot access the sink, faucet, or soap dispenser.

This study raises concerns that healthcare providers remain uninformed about ADA requirements to ensure the provision of full and equal access to care [7]. We found that most deficiencies clustered within examination rooms and restrooms and that ADA noncompliant 
architectural and equipment factors contributed to these deficiencies. The ADAAG provides specific guidelines for building and facility architectural requirements [11]. However, equal access to healthcare is dependent, in part, on staff and clinical managers being knowledgeable of ADA requirements. It is disturbing that very few managers expressed interest in ADA training of clinical staff. The U.S. DOJ's “Access to medical care for individuals with mobility disabilities" [5] was published to help educate healthcare providers on how the ADA applies to healthcare facilities and services. Previous studies have shown that knowledge of the ADA and accessible equipment can reduce the number of barriers to healthcare $[13,17]$; unfortunately few training programs exist for healthcare professionals [18-19]. It is hoped that upon adoption, the U.S. Access Boards' new "Proposed accessibility standards for medical diagnostic equipment” [7] will provide healthcare facilities and clinics with specific accessible medical equipment standards and serve as a catalyst for development of professional training for healthcare professionals. At a minimum, passage of the new standard may enable the U.S. DOJ to be better equipped to enforce the ADA with respect to medical facilities.

This study has several important limitations. First, our sample size was small. A larger sample may have resulted in different findings and allowed us to determine whether there were statistical differences in ADA compliance based on practice type. Second, we limited our scope to the subset of individuals with mobility disabilities who use a wheelchair; in the future, we plan to assess clinics for accessibility by individuals who use a more diverse range of mobility aids/devices. Third, we used the U.S. DOJ's "Access to medical care for individuals with mobility disabilities" [5] as our primary guide for evaluating accessibility. This guide does not address accessibility issues specific to medical instrumentation, such as radiology or rehabilitation equipment. Finally, we used a convenience sample of clinics in one geographical region rather than a randomly selected group. Managers who permitted us to visit may have been more confident in their practices' ADA compliance, and this could have biased our results. All surveyed clinics were located in facilities owned by a single, statewide healthcare network. Corporations have legal and compliance resources that small practice owners may not, so the offices we surveyed may have been more accessible than those leased by community medical groups. A more inclusive study of healthcare accessibility is warranted.

\section{CONCLUSIONS}

Despite potential limitations, this pilot study identified key obstacles to care among clinics affiliated with a statewide health network. The majority of clinics did not have access to a weight scale that could be used to weigh a wheelchair user nor own an accessible examination table. Most clinics examined patients while they remained seated in their wheelchair and requested patients bring someone to assist them in transferring to the examination table as needed. Additionally, most restrooms failed to comply with one or more ADA requirements, affecting the ability of wheelchair users to access the toilet or sink. We recommend clinics conduct selfassessments based on ADA guidelines and develop a remediation plan for achieving ADA compliance. Training for clinical managers and staff on the requirements of the ADA and how to assist individuals with mobility disabilities is also needed. These recommendations may yield demonstrable benefits in access to care for individuals with mobility disabilities, staff and patient safety, and clinical efficiency.

\section{ACKNOWLEDGMENTS}

\author{
Author Contributions: \\ Study conception and design: S. Williams, M. D. Stillman, \\ K. L. Frost, G. Bertocci. \\ Analysis and interpretation of the data: K. L. Frost, G. Bertocci, \\ C. Smalley, M. D. Stillman. \\ Drafting of manuscript: K. L. Frost, G. Bertocci, C. Smalley, \\ M. D. Stillman. \\ Critical revision of manuscript for important intellectual content: \\ K. L. Frost, G. Bertocci, M. D. Stillman. \\ Final approval of manuscript: K. L. Frost, G. Bertocci, \\ M. D. Stillman, S. Williams, C. Smalley. \\ Obtained funding: K. L. Frost, M. D. Stillman.
}

Financial Disclosures: The authors have declared that no competing interests exist.

Funding/Support: This material was based on work supported by the University of Louisville, Louisville, Kentucky, Intramural Research Incentive Grant program.

Institutional Review: The study was approved by the University of Louisville Institutional Review Board.

Disclaimer: The opinions expressed herein are those of the authors and do not necessarily reflect University of Louisville opinion. 


\section{REFERENCES}

1. Americans with Disabilities Act of 1990, Pub. L. 101-336, 104 Stat. 327 (Jul. 26, 1990).

2. Grabois EW, Nosek MA, Rossi CD. Accessibility of primary care physicians' offices for people with disabilities. An analysis of compliance with the Americans With Disabilities Act. Arch Fam Med. 1999;8(1):44-51.

[PMID:9932071]

http://dx.doi.org/10.1001/archfami.8.1.44

3. Bachman SS, Vedrani M, Drainoni ML, Tobias C, Andrew J. Variations in provider capacity to offer accessible health care for people with disabilities. J Soc Work Disabil Rehabil. 2007;6(3):47-63. [PMID:17989034] http://dx.doi.org/10.1300/J198v06n03_03

4. Morrison EH, George V, Mosqueda L. Primary care for adults with physical disabilities: Perceptions from consumer and provider focus groups. Fam Med. 2008;40(9): 645-51. [PMID:18830840]

5. U.S. Department of Justice. Access to medical care for individuals with mobility disabilities [Internet]. Washington (DC): U.S. Department of Justice; 2010 Jul. Available from: http://www.ada.gov/medcare_ta.htm

6. Patient Protection and Affordable Care Act, Pub. L. 111148, 124 Stat. 119 (Mar. 23, 2010).

7. U.S. Access Board. Proposed accessibility standards for medical diagnostic equipment. Notice of proposed rulemaking. Fed Regist. 2012;77:6915-39.

8. Neri MT, Kroll T. Understanding the consequences of access barriers to health care: Experiences of adults with disabilities. Disabil Rehabil. 2003;25(2):85-96.

[PMID:12554383]

http://dx.doi.org/10.1080/0963828021000007941

9. Veltman A, Stewart DE, Tardif GS, Branigan M. Perceptions of primary healthcare services among people with physical disabilities_-Part 1: Access issues. MedGenMed. 2001;3(2):18. [PMID:11549967]

10. Stillman MD, Frost KL, Smalley C, Bertocci G, Williams S. Health care utilization and barriers experienced by individuals with spinal cord injury. Arch Phys Med Rehabil. 2014;95(6):1114-26. [PMID:24565745] http://dx.doi.org/10.1016/j.apmr.2014.02.005

11. U.S. Access Board. Americans with Disabilities Act (ADA) Accessibility Guidelines for Buildings and Facilities. Appendix A to Part 1191-ADA [Internet]. Washington (DC): U.S. Access Board; 2002 Sep. Available from: http:// www.access-board.gov/guidelines-and-standards/ buildings-and-sites/about-the-ada-standards/background/ adaag

12. Winters JM, Story MF, Barnekow K, Kailes JI, Premo B, Schwier E, Danturthi S, Winters JM. Results of a national survey on accessibility of medical instrumentation for con- sumers. In: Winters JM, Story MF, editors. Medical instrumentation, accessibility and usability considerations. Boca Raton (FL): CRC Press; 2007. p. 13-27.

13. Pharr J. Accessible medical equipment for patients with disabilities in primary care clinics: Why is it lacking? Disabil Health J. 2013;6(2):124-32. [PMID:23507163]

http://dx.doi.org/10.1016/j.dhjo.2012.11.002

14. Kirschner KL, Breslin ML, Iezzoni LI. Structural impairments that limit access to health care for patients with disabilities. JAMA. 2007;297(10):1121-25.

[PMID:17356035]

http://dx.doi.org/10.1001/jama.297.10.1121

15. Pharr JR. Accommodations for patients with disabilities in primary care: A mixed methods study of practice administrators. Glob J Health Sci. 2014;6(1):23-32.

[PMID:24373261]

16. ADA National Network. Disability and discrimination at the doctor's office [Internet]. Rockville (MD): ADA National Network; 2013 [cited 2014 Dec 5]. Available from: http://adata.org/content/disability-and-discriminationdoctors-office

17. Pharr J, Chino M. Predicting barriers to primary care for patients with disabilities: A mixed methods study of practice administrators. Disabil Health J. 2013;6(2):116-23.

[PMID:23507162]

http://dx.doi.org/10.1016/j.dhjo.2012.11.003

18. Iezzoni LI, Ramanan RA, Drews RE. Teaching medical students about communicating with patients who have sensory or physical disabilities. Disabil Stud Q. 2005;25(1).

19. Kroll T, Beatty PW, Bingham S. Primary care satisfaction among adults with physical disabilities: The role of patientprovider communication. Manag Care Q. 2003;11(1):11-19. [PMID:12790061]

Submitted for publication January 8, 2015. Accepted in revised form May 20, 2015.

This article and any supplementary material should be cited as follows:

Frost KL, Bertocci G, Stillman MD, Smalley C, Williams S. Accessibility of outpatient healthcare providers for wheelchair users: Pilot study. J Rehabil Res Dev. 2015;52(6):653-62.

http://dx.doi.org/10.1682/JRRD.2015.01.0002

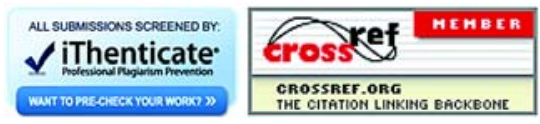


